Tempo Social; Rev. Sociol. USP, S. Paulo, 10(1): 165-184, maio de 1998.

\title{
Repensando a teoria da proletarização dos profissionais
}

\author{
MARLI DINIZ
}

RESUMO: A autora analisa a tese da proletarização dos profissionais com o objetivo de verificar até que ponto ela capta os processos reais de mudança que têm afetado as profissões. A questão central que a autora procura responder é se os profissionais assalariados por burocracias públicas e privadas preservam em medida considerável suas qualificações técnicas, o controle do conhecimento altamente especializado e sobre o processo de trabalho. Utilizando-se uma vasta bibliografia sobre o trabalho profissional em indústrias de diversos setores (metal, mecânico, eletrônico), conclui que as evidências de crescente assalariamento de algumas das chamadas profissões liberais não constituem suporte adequado para a tese da proletarização dos profissionais quando este termo é adequadamente entendido. As investigações têm mostrado que mesmo quando o profissional assalariado perde o controle sobre as condições em que trabalha, ele o mantém sobre o processo do seu trabalho; isto é, ele conserva sua autonomia técnica.

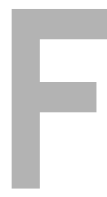

uncionalistas, neoweberianos e neomarxistas parecem concordar em que o conhecimento especializado dos profissionais - sua expertisegarante-lhes, ao contrário do que ocorre com outras categorias ocupacionais - e em particular com os trabalhadores manuais - uma considerável autonomia no trabalho. Para usar uma terminologia mais em voga, os profissionais teriam, individualmente, um extenso controle sobre o processo de trabalho ${ }^{1}$. As divergências situam-se na interpretação do processo pelo qual, nas sociedades modernas contemporâneas, esta autonomia estaria supostamente sendo solapada. Ritzer e Walczak (1988) argumentam que a autonomia do profissional, o controle que ele exercia sobre o processo de trabalho
UNITERMOS: profissionais, proletarização, desprofissionalização, autonomia técnica.

Texto integrante da mesa redonda Para onde vai a classe média, organizada pelos GT's Trabalho e Sociedade e Educação e Sociedade, no XX Encontro Anual da ANPOCS, de 22 a 26/10/1996.

Professora do Departamento de Sociologia e Metodologia em Ciências Sociais da UFF 
Sobre a autonomia dos profissionais nas diferentes vertentes teóricas da sociologia, cf. Diniz (1995).

2 Seguindo Weber, Ritzer e Walczak observam que a racionalidade formal "refere-se a indivíduos fazendo escolhas em termos de meios e fins. Neste caso, entretanto, esta escolha é feita por referência a regras, regulamentos e leis universalmente aplicadas. Estas, por seu turno, são derivadas de estruturas de grande escala, especialmente burocracias e a economia" (Ritzer \& Walczak, 1988, p. 3). Quanto à racionalidade substantiva, o seu aspecto distintivo "é que o esforço para encontrar o meio mais racional para a realização de fins é delimitado por um conjunto coerente de valores sociais" (Ritzer \& Walczak, 1988, p. 4). ou sobre a utilização de sua expertise está se tornando em larga medida coisa do passado, conservando-se apenas suas formas simbólicas, na medida em que critérios de racionalidade formal - com sua ênfase em estruturas, regras e regulamentos - são introduzidos como parâmetros do trabalho profissional. Os médicos, por exemplo, ou se tornam assalariados em grandes hospitais ou empresas de prestação de serviços de saúde - sujeitando-se a regras e regulamentos e a critérios de rentabilidade - ou se submetem à mediação de uma terceira parte (empresas de seguro médico ou o próprio Estado, entre outras) em seus contatos com os clientes, perdendo o controle da relação. Como consequiência, os critérios propriamente profissionais de racionalidade substantiva - com sua ênfase em valores tais como autonomia, autoridade sobre o cliente, altruísmo - tornam-se subordinados ou secundários ${ }^{2}$. A economia capitalista e as organizações burocráticas constituem os loci privilegiados do processo de racionalização formal e, por isso, nas sociedades capitalistas e nas organizações de grande porte os profissionais estariam se tornando cada vez mais assemelhados aos burocratas e aos capitalistas - com sua ênfase em eficiência, preditibilidade, calculabilidade e substituição de tecnologia humana pela não-humana (cf. Ritzer \& Walczak, 1988, p. 7). Este é o registro dominante - embora não seja o único - na literatura sobre processos de desprofissionalização, e as conclusões dos estudos apontam invariavelmente para a tendência à racionalização do trabalho dos profissionais - assalariamento, padronização da base cognitiva, especialização, rotinização dos procedimentos - e suas consequiências para o solapamento das bases sobre as quais eles tradicionalmente assentaram suas reivindicações por autonomia no trabalho, autoridade sobre os clientes, monopólio da prestação de serviços, poder e prestígio.

A versão marxista do processo de desprofissionalização é a tese da proletarização dos profissionais em cuja base está a seguinte analogia: o que vem ocorrendo com os profissionais é semelhante ao que ocorreu, primeiro, com os artesãos e, em seguida, com os operários especializados na virada do século. À sujeição ao controle formal do capital ocorrida com a venda da força de trabalho (assalariamento) seguiu-se a sujeição ao controle real quando os trabalhadores foram expropriados tanto do seu saber sobre o processo de trabalho quanto do controle sobre este mesmo processo, e submetidos a uma maciça desqualificação. A analogia tem algum fundamento ?

Antes de avançar nesta questão vale a pena examinar criticamente a tese da desqualificação do trabalhador especializado; pois se esta não se sustenta, então a analogia perde inteiramente o sentido e com ela a tese da proletarização dos profissionais. Com este propósito parece ser adequado tomar como referência o estudo de Braverman (1977) sobre a degradação do trabalho no séc. XX, um clássico da literatura neomarxista e um marco nas análises neomarxistas sobre o processo de trabalho, fixando apenas os principais pontos de sua argumentação. 


\section{Braverman e a degradação do trabalho}

Embora a compra e venda de força de trabalho exista desde a antigüidade, ela só se tornou uma relação predominante com o advento do capitalismo industrial. Ela constitui a diferença específica da produção capitalista.

O trabalhador vende sua força de trabalho - isto é, faz o contrato de trabalho - porque as condições sociais não lhe oferecem outro meio para ganhar a vida. Esta é, quase sempre, a única forma pela qual eles têm acesso aos meios de produção, agora propriedade dos capitalistas. Estes, por seu lado, desejando ampliar a sua unidade de capital convertem parte deste capital em salário. Assim é posto em movimento o processo de trabalho que é, de fato, um processo de expansão do capital e de criação do lucro, e que se realiza quando o capitalista emprega todos os meios para aumentar a capacidade de produção da força de trabalho que ele comprou e pôs em operação.

Na primeira fase do capitalismo industrial, a estratégia empregada pelo capital para aumentar a produção era obrigar o trabalhador à jornada mais longa possível. Entretanto, esta forma de extração da mais-valia deixava intacta a autonomia técnica e social do trabalhador especializado, que permanecia como seu próprio mestre e o mestre dos seus auxiliares não especializados. O núcleo do processo de trabalho continuava intacto: cada operação dependia ainda da força, destreza, rapidez e firmeza do trabalhador individual ao usar os instrumentos de trabalho. Por isso, era ainda formal a sujeição do trabalho ao capital. Tratava-se apenas do início da proletarização, da produção de uma classe operária subordinada à classe dos capitalistas e com esta em conflito.

O núcleo da tese de Braverman consiste na argumentação de que a divisão técnica do trabalho destrói a autonomia do trabalhador e retira dele o controle sobre o processo de trabalho. A análise do processo do trabalho consiste na separação de procedimentos que se somam na fabricação de um produto integral, mas todas eles executados por um mesmo trabalhador ${ }^{3}$; mas a divisão do trabalho, que é específica do capitalismo, fragmenta as tarefas em operações mais simples e repetitivas atribuídas a diferentes operários. Os diferenciais individuais de habilidade e perícia se reduzem ou mesmo desaparecem, e esta homogeneização do trabalho destrói o "capital" do trabalhador especializado. Em termos de mercado, a força de trabalho pode ser comprada mais barata como elementos dissociados do que como capacidade integrada num só trabalhador. Ao mesmo tempo em que esta "lógica do capital" destrói a perícia e a habilidade do trabalhador, também retira do seu controle o processo de trabalho. A gerência científica, encarnada no taylorismo, irá intensificar esta tendência.

Ao mesmo tempo que destrói o ofício como processo sob o controle do trabalhador, o capitalista o reconstitui, mas agora sob seu próprio controle, o controle gerencial. A gerência foi desde o início uma criação da produção capitalista para controlar o trabalho: a reunião dos trabalhadores numa oficina e a fixação da jornada de trabalho; a supervisão dos operários para
O exemplo de Braverman: o funileiro que tenha de produzir funis em quantidade não os fabrica um a um: antes, faz, primeiro, um gabarito; depois, risca na chapa a quantidade desejada de funis; corta-os todos, um a um; enrolaos etc. O funileiro "descobriu que maiores quantidades serão produzidas com menos trabalho e maior economia de tempo deste modo do que acabando cada funil individualmente antes de começar o seguinte" (Braverman, 1977, p. 74). 
4 A seguinte citação colhida num estudo de empresa brasileira no setor metalmecânico ilustra este ponto: "Os operadores de MFU, de modo geral, possuem muita destreza e experiência em lidar com máquinas para fabricar produtos diferenciados (pequenas séries, lotes e peças sob encomenda). Interpretam os desenhos do projeto, fixam e centralizam a peça, selecionam ferramentas, regulam a máquina, controlam o corte e a refrigeração da ferramenta e trocam a ferramenta quando necessário. Assim, são profissionais com longa experiência de trabalho valorizada e reconhecida pela empresa.

As funções dos operadores de MFCN são bastante reduzidas e menos exigentes em relação à qualificação. As principais operações realizadas por eles são: colocar a fita do programa, fazer a montagem da peça para usinagem e das ferramentas necessárias, colocar a máqui- assegurar sua diligência; a fixação de mínimos de produção etc. Mas foi com o advento da administração científica que a centralidade do controle sobre o processo do trabalho adquiriu dimensões sem precedentes. Para Taylor o controle era uma necessidade absoluta da gerência adequada, o que significava impor ao operário um plano rigoroso de execução do trabalho, destitui-lo de qualquer margem para deliberação. $O$ trabalho do cérebro foi separado do trabalho das mãos, a concepção da execução, a oficina do escritório. Cabia à gerência codificar em regras e fórmulas todo o conhecimento possuído pelos trabalhadores, e com base neste conhecimento planejar detalhadamente a tarefa atribuída a cada um na intensificada divisão técnica do trabalho: cada atividade na produção devia ser prevista, pré-calculada, experimentada, comunicada, alocada, ordenada, conferida, inspecionada, registrada.

Simultaneamente, a mecanização da produção de larga escala iria completar o processo de degradação do trabalho. Se o elemento fundamental na evolução da maquinaria industrial é a maneira pela qual suas operações são controladas, segue-se que no momento em que o controle da máquina foge das mãos do trabalhador que a opera, ou melhor, no momento em que a velocidade da máquina e a sequiência mecanizada ou automizada de suas operações predetermina os movimentos e o ritmo do operador, completa-se o processo de proletarização, de sujeição real do trabalho ao capital. Contemporaneamente isto ocorreria, por exemplo, com a introdução de tecnologia microeletrônica no processo produtivo (máquinas ferramentas de controle numérico - MFCN, robôs etc.) em substituição à tecnologia de base eletromecânica (máquinas ferramentas universais - MFU). O saber altamente especializado de um torneiro-mecânico que controla uma MFU lhe é expropriado e transferido para uma fita perfurada (programa) que comandará uma MFCN em todos os detalhes de sua operação ${ }^{4}$. Conseqüentemente, "o mecânico especializado é, por esta inovação, considerado deliberadamente obsoleto como a ventoinha ou o telégrafo de Morse, e via de regra substituído por três espécies de operadores" (Braverman, 1977, p. 173) ${ }^{5}$.

Observe-se, finalmente, que o processo de degradação do trabalho no sistema capitalista de produção não afetaria apenas os operários das fábricas. Segundo Braverman, a mecanização e racionalização dos escritórios rotinizou os processos mentais exigidos dos funcionários, ou fez com que se tornassem uma parcela menor do que a das operações manuais no conjunto do trabalho; por outro lado, os salários pagos a estas categorias de empregados desceram ao nível daqueles pagos aos trabalhadores manuais menos qualificados. Desta forma, e por suas condições de trabalho, o segmento dos funcionários de escritório tornou-se um "vasto proletariado sob nova forma" (Braverman, 1977, p. 300). O mesmo processo de degradação do trabalho e de proletarização estaria começando a afetar as "camadas médias" do emprego: engenheiros, técnicos, quadro científico, os níveis inferiores da supervisão e da gerência, empregados especializados e "liberais" etc. Entre desenhistas e técnicos, entre engenheiros e contadores, entre enfermeiros e professo- 
DINIZ, Marli. Repensando a teoria da proletarização dos profissionais. Tempo Social; Rev. Sociol. USP, S. Paulo, 10(1): 165-184, maio de 1998.

res, entre os pequenos gerentes, chefes e supervisores, na consciência de todas estas categorias de assalariados "a forma proletária começa a afirmar-se e a imprimir-se" a despeito dos privilégios de que ainda gozam. Entretanto, Braverman cautelosamente evita prever para as "camadas médias" o mesmo destino proletário que reconhece para os empregados de escritório; limita-se a apontar os seus "sintomas".

\section{Críticas à tese da degradação do trabalho}

A despeito do impacto da tese de Braverman nos estudos sobre o processo de trabalho e sua imediata adoção pelos neomarxistas como ponto de referência, bem cedo as críticas se tornaram numerosas o suficiente para limitar o alcance que inicialmente ela parecia ter. De modo geral, inúmeros estudos vieram mostrar que as associações estabelecidas por Braverman por exemplo, entre tecnologia e desqualificação do trabalho - são bem mais complexas do que ele fazia crer; que importantes fatores mediatizantes de natureza macrossocial ou macroeconômica foram por ele negligenciados em favor de uma abordagem restrita aos fatores localizados "no ponto de produção"; que em inúmeros casos a tese é simplesmente desconfirmada por detalhados estudos in loco do processo de trabalho. No que segue são apresentados de forma sintética exemplares desta literatura crítica.

Em Braverman e nos neomarxistas o controle do processo de trabalho parece ser um propósito dominante do capitalista. Como observou Wilkinson, para Braverman a tecnologia "não é apenas um dado exterior às empresas, mas ela é deliberadamente concebida para aumentar o controle da direção sobre o processo de produção e reduzir o custo da mão-de-obra, desconsiderando e desqualificando progressivamente o trabalho" (Wilkinson, 1984, p. 448). E entre escolher uma tecnologia que reduza custos e outra que maximize o controle, o capitalista de Braverman escolherá, aparentemente, a última (cf. Jones \& Wood, 1984, p. 409). Da mesma forma, os que seguiram a trilha aberta por Braverman às vezes se esquecem de que "o foco básico do interesse do capitalista é a acumulação, não o controle direto de todos os aspectos do processo de trabalho como um fim em si mesmo" (Whalley, 1986, p. 239).

Se outras formas de controle estão ao alcance do capitalista, não há por que supor a priori que a desqualificação do trabalho será a estratégia preferida (Whalley, 1986); os proponentes da tese da desqualificação "ignoram a vasta literatura que sugere que sob condições de rápida mudança na tecnologia e no ambiente das empresas um desenho organizacional mais adequado implica em emprego mais flexível do trabalho e maior autonomia ao trabalhador" (Whalley, 1984, p. 123). Identicamente, "não se obtém necessariamente um ótimo econômico por uma redução máxima do trabalho vivo" (Kern \& Schumann, 1984, p. 399).

A classe capitalista de Braverman é excessivamente coesa na adoção de estratégias de controle, e a classe trabalhadora excessivamente dócil ao na no ponto de partida, iniciar a operação e fazer a supervisão da usinagem. Como a interpretação do desenho é realizada antes e o próprio programa contém a velocidade exata do corte, do fluxo de refrigeração e da sucessão de ferramentas, resta ao operador muito pouco a decidir, assumindo na prática a função de monitor da máquina" (Sousa, 1988, p. 103).

Por via de regra o trabalho executado pelo oficial mecânico especializado ao operar uma MFU foi fracionado em três partes, cada qual atribuída a um trabalhador que pode ser apenas semiespecializado: o "programador da peça", que registra as especificações do desenho técnico numa folha de planejamento previamente tabulada e padronizada; o operador da máquina que converte a folha de planejamento numa linguagem (programa/ fita perfurada) legível para a MFCN; o operário que monitora as operações da MFCN. 
6 Sindicatos que organizam trabalhadores em ocupações especializadas para a admissão nas quais prevalece o aprendizado (apprenticeship) ou treinamento equivalente.

Para os sindicatos trata-se não apenas de preservar a descrição de certas posições (jobs) como "artesanais", mas de elevar outras a este mesmo status e de controlar o sistema de apprenticeship. Tentam com isso controlar o oferta no mercado de trabalho (restringindo oportunidades de aprendizagem ou aumentando a duração desta). controle via desqualificação do trabalho, uma versão incorreta dos fatos e da realidade histórica, pelo menos no que concerne aos Estados Unidos na virada do século. Braverman ignora não apenas a divisão entre os capitalista quanto à adoção do taylorismo, mas também os conflitos entre capitalistas e os "gerentes científicos" e as lutas dos trabalhadores contra a racionalização do trabalho (Stark, 1980). Mais recentemente, estudos de caso sobre introdução de tecnologia de controle numérico mostram que as "qualificações das diferentes categorias de trabalhadores dependem da luta pelo controle no interior das empresas e não simplesmente das características próprias a uma dada tecnologia" (Wilkinson, 1984, p. 454).

A imagem elaborada (e idealizada) por Braverman de uma sociedade povoada de trabalhadores especializados (skilled craftsmen) não reflete corretamente a composição da força de trabalho na virada do século nos Estados Unidos. Embora os trabalhadores especializados fossem centrais no processo produtivo, sua importância numérica era reduzida e a grande massa era composta de operários semi-especializados ou não-especializados. Desta forma, o cenário de um processo unilinear e massivo de desqualificação do trabalho ou de proletarização é historicamente inexato (cf. Stark, 1980).

Braverman e os neomarxistas sistematicamente ignoram variáveis macroeconômicas ou macrossociais na explicação dos níveis de qualificação dos trabalhadores, privilegiando fatores relativos ao local de trabalho ("ponto de produção"), certamente porque estes últimos facilitam a ênfase nas estratégias de controle. Todavia, "a introdução de novas tecnologias de produção não é guiada simplesmente por um objetivo universal de controle, mas ditada de maneira crucial por fatores tais como as características do mercado de trabalho e de produtos, a organização sindical e patronal (nas empresas e em setores industriais particulares) e por outras características de estratégia e táticas de gestão" (Jones \& Wood, 1984, p. 409). Na Inglaterra, o declínio de algumas regiões, flutuações nos gastos governamentais, escassez de matéria prima, a preponderância de pequenas empresas e as altas taxas de falência na indústria enfraqueceram os sindicatos de trabalhadores especializados ${ }^{6}$ e reduziram sua capacidade de controle sobre a descrição de tarefas (craft control of job description) ${ }^{7}$; trata-se, todavia, de "um aspecto constante da vida industrial britânica que vem do século dezenove", e não de alguma "perda de controle" trazida pelo "capital monopolista" (Lee, 1981, p. 71).

Braverman e os neomarxistas não distinguem entre desqualificação do trabalho e desqualificação do trabalhador (cf. Lee, 1981; Whalley, 1984). Uma posição (job) pode ser desqualificada, mas o trabalhador absorvido em outras tarefas especializadas criadas pela mudança de tecnologia. De qualquer maneira, se o interesse está no exame da proletarização da força de trabalho, o importante é o total das oportunidades que o trabalhador tem para exercer suas habilidades, e estas não estão necessariamente determinadas somente ao nível do local de trabalho. Outros fatores importantes são a demanda agregada e o nível de emprego, o crescimento de novos setores dinâmicos 
na indústria, assim como outras variáveis macroeconômicas.

Várias pesquisas têm mostrado que a introdução de máquinas de controle numérico não leva necessariamente à desqualificação do trabalho. Num estudo de trinta e duas empresas (pequeno e médio porte) da indústria mecânica francesa, Cavestro (1984) observou que o comando numérico permite uma gama diversificada de intervenções por parte do operador, e que certos conhecimentos tradicionais (conhecimento dos materiais, o "sentido da frisagem e do torneamento") e experiências convencionais próprias dos operários qualificados são indispensáveis na operação das máquinas de controle numérico. Pesquisando empresas em setores dinâmicos da industria alemã (automobilística, construção mecânica, química), Kern e Schumann detectaram um processo de reprofissionalização da força de trabalho através da atenuação da divisão do trabalho, o inverso do que haviam encontrado em pesquisa nos anos setenta: "quanto mais se avança em direção de produtos de qualidade, de alta complexidade, e em direção ao emprego em grande escala de novas tecnologias, mais as concepções de uma utilização ótima do trabalho se orientam para definições mais amplas de tarefas e para a utilização mais completa das qualificações" (Kern \& Schumann, 1984, p. 402). Na indústria britânica, "a introdução de maquinaria computadorizada provocou uma mudança, mas não destruição das habilidades tradicionais; no geral, o efeito da mudança tecnológica foi o de transferir os requisitos de qualificação da produção para a manutenção" (Lee, 1981, p. 72). Este mesmo efeito de transferência foi observado por Freyssenet (1984) numa empresa francesa do setor automobilístico (com requalificação dos operários de produção) e por Souza (1988) em empresas brasileiras nos setores automobilístico e metalmecânico. Reavaliando a experiência internacional com introdução de tecnologia de controle numérico, Falabella (1988) observa que em alguns países escandinavos os operadores desenham a fita (perfurada) e, conseqüentemente, controlam o processo de transformação do seu saber produtivo em software. Examinando pesquisas empíricas conduzidas na Inglaterra sobre novas tecnologias e desqualificação do trabalho, Gill concluiu que "recentes trabalhos empíricos sobre o impacto de novas tecnologias sobre o processo de trabalho não permitem concluir por uma tendência inelutável à desqualificação do trabalho" (Gill, 1984, p. 563). Após um exame da literatura específica e de estudos empíricos sobre o impacto de tecnologias de base microeletrônica sobre as qualificações dos trabalhadores, Schmitz concluiu que em si mesma esta tecnologia não é desqualificante, embora forneça à gerência recursos poderosos para o controle do processo de trabalho; entretanto, há restrições a este controle e há efeitos indesejáveis: "a adoção de um modelo taylorista rígido é contraproducente no caso da automação. As interrupções imprevistas e o alto custo da ociosidade dos equipamentos exigem acima de tudo uma força de trabalho flexível, envolvida e atenta, e a responsabilidade passa a ser uma qualidade mais importante do que a simples qualificação técnica" (Schmitz, 1985, p. 667).

Todas as observações anteriores, e as inúmeras outras que pode- 
riam ser acrescentadas ao estoque considerável de críticas à tese de Braverman e dos neomarxistas, não significam adesão às teses sobre a sociedade pósindustrial na qual máquinas sofisticadas se encarregariam das tarefas rotineiras, liberando para outras funções mais "nobres" uma força de trabalho estável, bem remunerada e altamente qualificada ${ }^{8}$. De fato, não se trata aqui de adjudicar entre teorias antagônicas, mas simplesmente de demonstrar que se a tese da degradação do trabalho não tem a generalidade que reclama no seu próprio campo de aplicação - isto é, entre os trabalhadores manuais -, então, não constitui ela uma base sólida para a tese da proletarização dos profissionais.

\section{Examinando a tese da proletarização dos profissionais.}

À semelhança da imagem equivocada que Braverman apresenta da composição da força de trabalho no séc. XIX nos Estados Unidos, os neomarxistas parecem identificar nas sociedades mais avançadas na virada do século uma camada diversificada de profissionais autônomos exercendo suas atividades sob a forma "liberal", mas submetidos pela lógica da acumulação capitalista ao longo do presente século a um inexorável processo de assalariamento e, conseqüentemente, de perda de controle sobre seu trabalho e de desqualificação.

Entretanto, seria adequado lembrar, ainda a respeito de Braverman, que "as atuais camadas médias não tiveram um passado róseo. De fato, não tiveram qualquer passado, dado que muitas delas não existiam. Elas não foram proletarizadas: foram criadas" (Gagliani, 1981, p. 281). Igualmente, a maioria das profissões contemporâneas é de criação recente e já nasceu assalariada. Analisando os dados do censo americano para 1970, Freidson (1986) concluiu que a tendência ao assalariamento tem sido um processo lento que afeta rigorosamente apenas aquelas quatro categorias de profissionais que no passado caracterizavam-se pelo exercício autônomo: médicos, dentistas, advogados (mas não os juízes) e arquitetos. Os engenheiros, surgidos no séc. XIX, foram desde o início assalariados ou pelo Estado ou por grandes empresas. Ademais, somadas as quatro categorias "clássicas", elas correspondem, ainda segundo Freidson, a apenas $6 \%$ do total da força de trabalho técnicoprofissional. Constituindo uma exceção mais do que a regra, é absolutamente incorreto tomá-las como representativas de tendências para o universo de profissionais.

No Brasil, o sistema de ensino superior só se institucionalizou e diversificou a partir da década de trinta, com a criação das primeiras universidades, o que significa que a maioria das profissões hoje constituídas é bastan-

8 A formulação clássica sobre a sociedade pósindustrial é de Bell (1977). te recente. Nasceram quase todas como profissões assalariadas, fruto da expansão do aparelho estatal e das empresas do setor produtivo privado. Poucas haviam sido regulamentadas até a década de 60 (cf. Tabela 1). 


\begin{tabular}{|c|c|c|c|c|c|c|c|}
\hline Ano & $\begin{array}{l}\text { Nível } \\
\text { médio }\end{array}$ & $\begin{array}{c}\text { Nível } \\
\text { superior }\end{array}$ & Total & Ano & $\begin{array}{l}\text { Nível } \\
\text { médio }\end{array}$ & $\begin{array}{c}\text { Nível } \\
\text { superior }\end{array}$ & Total \\
\hline 1931 & 1 & 2 & 3 & 1963 & - & 1 & 1 \\
\hline 1933 & - & 1 & 1 & 1966 & 5 & 31 & 36 \\
\hline 1942 & 1 & - & 1 & 1967 & - & 4 & 4 \\
\hline 1945 & 2 & - & 2 & 1968 & 11 & 3 & 14 \\
\hline 1946 & 1 & 1 & 2 & 1969 & - & 3 & 3 \\
\hline 1952 & - & 1 & 1 & 1970 & 1 & 2 & 3 \\
\hline 1956 & 4 & 1 & 5 & 1971 & 1 & 7 & 8 \\
\hline 1957 & - & 2 & 2 & 1973 & - & 2 & 2 \\
\hline 1960 & 1 & 1 & 2 & 1978 & 2 & 3 & 5 \\
\hline 1961 & 2 & 2 & 4 & 1979 & 1 & 5 & 6 \\
\hline \multirow[t]{2}{*}{1962} & 1 & 3 & 4 & 1980 & - & 2 & 2 \\
\hline & & & & Total & 34 & 76 & 110 \\
\hline
\end{tabular}

Tabela 1 - Profissões regulamentadas Fonte: CIEE, 1981

Das profissões mais antigas, a engenharia nasceu predominantemente assalariada e restariam como profissionais tipicamente "liberais" os médicos, os dentistas, os advogados e os arquitetos ${ }^{9}$. Ainda que não existam estatísticas em séries históricas mais longas relativas à posição na ocupação, presumivelmente estas quatro categorias profissionais tornaram-se crescentemente assalariadas ao longo do tempo; entretanto, somadas elas constituíam em 1985 aproximadamente $18 \%$ de todo o estoque de profissionais de nível superior no país (MEC, s.d.), o que ainda é uma cauda relativamente pequena num cão muito grande, para usar a expressão de Freidson. Note-se, todavia, que com exceção dos médicos, a proporção de assalariados tem diminuído entre os dentistas, advogados e arquitetos (tabela 2).

\begin{tabular}{lrrrrrrrrrrr}
\hline Anos & \multicolumn{3}{c}{1970} & \multicolumn{3}{c|}{1980} & \multicolumn{3}{c|}{1988} \\
\hline Profissões & $\begin{array}{c}\text { Conta } \\
\text { própria }\end{array}$ & $\begin{array}{c}\text { Empre- } \\
\text { gado }\end{array}$ & gadore- & própria & gado & gador & própria & gado & gador \\
\hline Engenheiro & 11.8 & 1.4 & 86.8 & 9.1 & 2.8 & 88.1 & 8.6 & 1.5 & 89.9 \\
Arquiteto & 23.2 & 4.7 & 72.1 & 42.8 & 5.6 & 51.6 & 44.7 & 4.5 & 50.8 \\
Médico & 32.0 & 0.3 & 67.7 & 24.8 & 7.3 & 67.9 & 26.1 & 6.2 & 67.6 \\
Dentista & 69.6 & 0.3 & 30.1 & 64.7 & 4.0 & 31.3 & 66.6 & 11.7 & 21.7 \\
Advogado & 47.4 & 0.6 & 51.9 & 49.3 & 5.3 & 45.4 & 53.8 & 7.1 & 30.1 \\
\hline
\end{tabular}

Tabela 2 - Posição na ocupação para algumas profissões: 1970, 1980, 1988. Fonte: IBGE - Amostras dos Censos de 1970 e 1980; PNAD - 1988.

Delimitado assim o possível âmbito de aplicação da tese da proletarização dos profissionais, a questão central é se o assalariamento implica em desqualificação e em perda da autonomia técnica no trabalho ou, em outras palavras, se ao assalariamento segue-se o controle do trabalho dos profissionais por hierarquias gerenciais heterônomas, e nestes termos a questão pode ser estendida aos profissionais que, como os engenheiros, não tiveram um passado "liberal". Como se verá, a tese da proletarização dos profissionais encontra escasso suporte na literatura. A resposta de Freidson (1986) é

9 Sobre as origens assalariadas da engenharia no Brasil, cf. Diniz (1995). 


\footnotetext{
${ }^{10}$ Num estudo sobre a medicina, Freidson (1970) mostrou que os médicos podem dar ordens e intervir nos vários serviços hospitalares sob justificativa da ocorrência de uma real ou imaginária (mas freqüentemente ambígua) situação de "emergência médica".
}

que o assalariamento não conduz à perda da autonomia técnica, embora certamente implique alguma perda do controle sobre os termos e condições do trabalho. Trata-se, segundo Freidson, de um paradoxo: os profissionais assalariados são simultaneamente dependentes e autônomos; permanecem com o controle do processo de trabalho, mas dentro de circunstâncias que eles não controlam. Basicamente, a gerência - no setor privado - ou os administradores do Estado - no setor público - controlam a alocação de recursos, e ao fazê-lo estabelecem os limites dentro dos quais os profissionais podem exercer a autonomia técnica. Trata-se, evidentemente, de uma limitação real; mas a margem de liberdade e independência no trabalho de que ainda assim gozam os profissionais não é de forma alguma trivial, sobretudo se comparada à de outras categorias de empregados. Em ambientes organizacionais em que o profissional é dominante na divisão do trabalho (engenheiros em empresas de consultoria técnica, advogados em grandes escritórios ou firmas de advogacia, médicos em hospitais etc.) sua autonomia técnica inclui a autoridade para controlar e coordenar o trabalho de outros empregados, uma função normalmente alocada à gerência em outros contextos (cf. Freidson, 1993). O exemplo dos hospitais é paradigmático: na medida em que os médicos prestam e controlam o serviço básico, também o controle dos serviços de suporte (paramédicos) ocorre por ordens deles e não da gerência administrativa que mantém, entretanto, a autoridade sobre a alocação de recursos ${ }^{10}$. Dent (1993) refere-se a um tipo de autonomia responsável para descrever o que ocorre nos hospitais ingleses por força das crescentes pressões do governo por redução nos custos dos serviços de saúde, com um visível impacto sobre a atividade dos médicos que perderam muito da antiga autonomia; eles ainda retêm o controle sobre as situações de trabalho, mas não podem mais comprometer recursos adicionais como conseqüência unicamente de suas decisões clínicas. As decisões alocativas tornaram-se prerrogativas da gerência.

Estudos sobre os engenheiros sugerem que a tese da desqualificação do profissional assalariado é, no mínimo, conceitualmente equivocada e pode ser questionada também com relação às estratégias gerenciais de controle. Os estudos de Whalley $(1984 ; 1986)$ e de Whalley \& Crawford (1984) sobre duas empresas britânicas (uma no setor de produção de equipamentos eletrônicos e de laser para a indústria gráfica; a outra no setor de produção de componentes metálicos para a indústria automobilística) mostram, em primeiro lugar, que no caso dos engenheiros o conceito importante para a análise da desqualificação é o de carreira e não o de tarefa (task) ou o de posição (job) no processo produtivo. Pois, como observa Whalley, "mesmo se determinadas tarefas tornam-se rotinizadas ou desqualificadas (deskilled) - o que não é inevitável, mesmo quando tecnicamente possível -, o que é importante para o engenheiro é se o conjunto de oportunidades disponíveis para ele no mercado de trabalho oferece as ocasiões, durante uma carreira normal, para o exercício da autonomia e para o uso de suas habilidades" (Whalley, 1984, p. 126). Numa das empresas estudadas, as posições ou tarefas rotinizadas 
DINIZ, Marli. Repensando a teoria da proletarização dos profissionais. Tempo Social; Rev. Sociol. USP, S. Paulo, 10(1): 165-184, maio de 1998.

eram apenas um ponto de passagem, pois os engenheiros eram encorajados a avançar na carreira até os cargos de gerência ${ }^{11}$. Ademais, o engenheiro pode mover-se no mercado de trabalho, trocando uma posição desqualificada numa empresa por outra mais qualificada em outra empresa. Em segundo lugar, é necessário distinguir a desqualificação da posição da desqualificação do profissional. Na outra empresa estudada, a rotinização de certas tarefas não desqualificava o engenheiro por força de dois mecanismos: a gerência evitava a concentração de tarefas rotinizadas em postos de trabalho particulares, e procurava assegurar-se de que postos de trabalho rotinizados não fossem alocados permanentemente a um grupo particular de engenheiros.

Embora Whalley nunca enderece diretamente a questão, ele sugere que pelo menos nas duas empresas estudadas o trabalho dos engenheiros é susceptível de algum grau de rotinização, mas nada semelhante ao grau de taylorização a que pode ser submetido o trabalho do operário industrial; por outro lado, ele não sugere em momento algum que o saber do engenheiro possa ser expropriado, desqualificando o profissional. Assim, o interesse das suas pesquisas reside na demonstração de que, ao contrário do que propõe a tese da degradação do trabalho, a gerência não está nem necessariamente interessada nem compelida pela "lógica do capital" a desqualificar o trabalho do engenheiro. Pelo contrário, a "lógica do capital" pode requerer que as tensões entre expertise técnica e maximização do lucro sejam dissolvidas ou atenuadas por estratégias que garantam a autonomia do profissional e, por esta via, a permanência na empresa de um "empregado confiável” (Whalley, 1986).

Ao contrário das de Whalley, as pesquisas de Zussman em duas empresas americanas (numa, produção de componentes metálicos para máquinas; noutra, produtos eletrônicos) respondem diretamente à questão da desqualificação do trabalho dos engenheiros. Adquirida principalmente na experiência com indústrias e processos muito particulares, a expertise dos engenheiros em ambas as empresas é quase idiossincrática e, conseqüentemente, altamente resistente à racionalização. $\mathrm{O}$ processo de especialização ocorrido nas últimas décadas anteriores à pesquisa não resultou em desqualificação dos engenheiros os quais, por outro lado, percebem o trabalho nestas posições mais especializadas como parte do desenvolvimento da carreira. Em ambas as empresas os engenheiros gozam de considerável autonomia no trabalho, inclusive para distribuir seu tempo entre os diversos projetos de que simultaneamente participam, e embora poucos deles tenham autoridade formal sobre os operários, muitos exercem de fato esta autoridade: verificam a qualidade do trabalho de produção, supervisionam os operários que constroem as máquinas, e até mesmo concebem os componentes e as seqüências do próprio processo de trabalho dos operários. Em síntese, não foram encontradas evidências de proletarização ou, num sentido mais amplo, evidências de que os engenheiros "têm sido, ou estão a caminho de ser absorvidos na classe operária” (Zussman, 1984, p. 224).

Nesse ponto, e em vez de acrescentar outros exemplos aos anterio-
${ }^{11}$ Como nota Whalley (1984) e Whalley \& Crawford (1984), na Inglaterra a carreira de um engenheiro normalmente engloba diversas posições distribuídas numa hierarquia que se estende do nível do "técnico" até o do "gerente", passando pelo de "engenheiro". 
res, melhor será registrar que mesmo entre os neomarxistas a extensão da tese de Braverman para o âmbito das profissões é claramente questionada. Por exemplo, para Derber "os profissionais, ao contrário dos operários, resguardaram do emprego dependente aquilo que emergiu como o fundamento da sua auto-estima e status peculiar: uma considerável medida de preservação das suas competências técnicas e do continuado controle de conhecimento altamente especializado. Assim, os profissionais retêm uma autoridade anômala invejada e inatingível por outros empregados, a autoridade da profissão e da expertise, mesmo em face do emprego subordinado" (Derber, 1983a, p. 317). A especialização associada ao trabalho dos profissionais não significa fragmentação nem implica em desqualificação, mas em aprofundamento do conhecimento e das habilidades técnicas. Num trabalho posterior, Derber observa que o termo "patrocínio" (sponsorhip) é mais adequado do que assalariamento para descrever a diversidade das formas de inserção dos médicos no mercado: os "patrocinadores" ou provedores de capital (hospitais, empresas de seguro-saúde, clínicas particulares etc.) não são basicamente empregadores capitalistas e a fragmentação de seus interesses de classe enfraqueceu sua capacidade de exercer controle sobre o trabalho dos médicos os quais contam com "formidáveis recursos próprios para exercer controle e para resistir a ele" (Derber, 1983b, p. 563). Quanto ao profissional "liberal"que se torna assalariado, o que ele perde ao entrar numa relação de emprego é o controle sobre os fins do seu trabalho, já que ele não formula nem influencia as políticas da organização que o emprega, resultando disso uma perda do sentido ético do trabalho, dos valores aos quais ele deveria servir (cf. Derber, 1983a).

Que Derber chame a isto de "proletarização ideológica" parece ser uma escolha puramente arbitrária e sem conexão com a tese clássica do marxismo. Mais importante é observar que para várias categorias de profissionais assalariados nem mesmo a "proletarização ideológica" ocorre, já que a profissão nasceu subordinada a hierarquias gerencias heterônomas - eles jamais tiveram efetivamente o controle das políticas organizacionais e é provável que muitos não a desejem. Para os "liberais" que de fato experimentaram um processo de assalariamento, a questão é saber se obter o controle sobre os fins do seu trabalho é mais importante do que conservar a autonomia técnica para a manutenção de sua identidade profissional. Pois, como observou Larson, o assalariamento só conflita com as expectativas profissionais quando o que o profissional aspira é obter poder na organização, e não apenas preservar a autonomia técnica no desempenho das tarefas; porque numa organização o poder - isto é, a legitimidade e a capacidade para formular políticas - é uma propriedade não da função profissional, mas da função gerencial (Larson, 1977, p. 198). Ainda assim - e num esforço de fidelidade às categorias marxistas de análise -, Larson (1980) concede que o assalariamento objetivamente conduz à "alienação econômica" (sujeição formal do profissional à autoridade heterônoma do capitalista ou do gerente estatal), e que esta contém a semente 
DINIZ, Marli. Repensando a teoria da proletarização dos profissionais. Tempo Social; Rev. Sociol. USP, S. Paulo, 10(1): 165-184, maio de 1998.

da "alienação organizacional" (objetivamente, o trabalho em grandes organizações implica para o profissional numa "cooperação forçada" e, em princípio, em sujeição às normas e critérios burocráticos); entretanto, a expertise do profissional, por sua relevância e escassez, e porque falta à gerência heterônoma a competência para controlá-la, constitui uma barreira segura à "alienação técnica" (perda do controle sobre a execução do trabalho), e não ocorrendo esta não se produz a fusão das alienações necessárias para o surgimento da clássica condição proletária.

Evidentemente, Larson está atenta para a existência de ocupações cujo status profissional é bastante "diluído" pela ausência de uma base cognitiva consistente. Desta forma, os riscos da condição proletária estão desigualmente distribuídos. Quando a profissão conta com uma base cognitiva independentemente desenvolvida, estabelecida e validada - isto é, uma base cognitiva que independe do locus da sua utilização -, o assalariamento ou o emprego em grandes organizações dificilmente expõe o profissional aos riscos da racionalização do trabalho. O contrário ocorre com os profissionais cujos títulos resultam mais da generalização do credencialismo acadêmico (e da preferência dos empregadores por empregados com educação de nível superior, independentemente do conteúdo desta e da natureza das posições ou cargos a serem preenchidos) do que de uma firme inserção na divisão social do trabalho. De fato, a maioria dos casos em que ocorre racionalização do trabalho mental refere-se a profissionais assalariados em posições subordinadas, e cujas credenciais acadêmicas não são requeridas como resultado de necessidades técnicas das organizações empregadoras, mas de mecanismos de seleção social artificialmente estimulados pelo credencialismo generalizado ${ }^{12}$.

Isto posto, restaria ver os resultados de alguns estudos sobre o processo de "proletarização" (já agora, entre aspas) dos profissionais no Brasil. As teses de Braverman estimularam inúmeras pesquisas sobre o impacto da introdução de novas tecnologias sobre o processo de trabalho na indústria nacional, mas o processo de trabalho dos profissionais foi largamente ignorado $^{13}$. Via de regra, alguns raros cientistas sociais voltaram sua atenção, direta ou indiretamente, para o processo de assalariamento de algumas profissões "clássicas": no primeiro caso está a pesquisa de Donnangelo (1975) sobre os médicos na região metropolitana de São Paulo, e no segundo o ensaio de Durand (s.d.) sobre a profissão de arquiteto, ambos elaborados anteriormente ao trabalho de Braverman. O livro de Prandi (1982) sobre os "favoritos degradados" está mais sintonizado com o espírito da bravermania, pretende ser uma análise válida para todo o universo de profissionais, obedece às categorias de análise de um marxismo ortodoxo, mas não apresenta qualquer evidência de degradação do trabalho dos profissionais ${ }^{14}$.

A pesquisa de Donnangelo, conduzida com uma amostra de 905 médicos ${ }^{15}$ distribuídos por diferentes especialidades, revela a diversidade das formas de trabalho que caracteriza a medicina, e comprova que o assalariamento tende a se tornar a forma predominante: embora apenas $28 \%$ dos médicos
${ }^{12} \mathrm{O}$ credencialismo generalizado e a conseqüente "inflação de diplomas" estimula os empregadores a recrutar pessoal de nível superior mesmo quando as posições ou cargos a serem preenchidos exigem apenas educação de nível médio. $\mathrm{Na}$ pior das hipóteses, o diploma serve como critério inicial de seleção.

${ }^{13}$ Uma exceção parece ser o trabalho de Luz (1989) sobre o impacto da introdução do computador no trabalho dos contadores.

${ }^{14}$ Mais precisamente, o livro de Prandi trata das relações entre degradação do ensino universitário e degradação do mercado de trabalho profissional no Brasil. O "capital monopolista" (o modelo de desenvolvimento capitalista) é, previsivelmente, o vilão da história.

${ }^{15} \mathrm{~A}$ autora utilizou os cadastros do IBGE, a partir dos quais foi elaborada uma listagem de 5.381 médicos em atividade na grande São Paulo, diplomados até 1968. Desta listagem retirou-se uma amostra de 1.166 médicos, reduzida a 905 devido à "não-cobertura" de 261 casos. 
${ }^{16} 64,5 \%(\mathrm{n}=584)$ dos médicos da amostra trabalha exclusiva ou predominantemente em organizações, o que não significa que estejam todos submetidos ao mesmo grau de assalariamento. Mas todos os assalariados "puros" $(\mathrm{n}=253)$ trabalham em algum tipo de organização.

${ }^{17}$ Grifo nosso.

${ }^{18}$ Grifo nosso.

${ }^{19}$ Veja-se ainda a tabela 1 neste artigo. estivesse em condições exclusivas de trabalho assalariado, o assalariamento estendia-se efetivamente à quase totalidade da amostra $(83,4 \%)$, correspondendo a modalidade exclusivamente liberal a apenas $8,4 \%$ dos profissionais. Embora a autora não procure estabelecer associações entre o assalariamento e a autonomia profissional, é possível inferi-las através da relação entre "medicina de organizações" (hospitais, clínicas etc.) e controle do trabalho ${ }^{16}$ : como observa Donnangelo, "a proporção relativamente baixa de trabalho isolado e a predominância de hospitais entre as organizações, faz supor que considerável parcela dos profissionais se encontra atualmente sujeita, em seu trabalho, a algum tipo de direção ou controle. A julgar, entretanto, pelas descrições oferecidas pelos médicos a respeito de sua atividade profissional, esse controle parece referir-se menos aos aspectos propriamente técnicos, envolvidos na execução de cada tarefa, e mais à necessidade de racionalizar o uso coletivo de instrumentos de trabalho"(Donnangelo, 1975, p. 71) $)^{17}$. Ou ainda: "sem perder o controle técnico sobre seu trabalho, o médico deve, entretanto, subordiná-lo ao modo como estão estruturadas as relações entre a clientela e as instituições, e entre estas e os demais médicos ou outros profissionais, e ao tipo de controle que a instituição exerce sobre os instrumentos de trabalho" (Donnangelo, 1975, p. 73) ${ }^{18}$.

O ensaio de Durand sobre os arquitetos apresenta escassas indicações sobre a extensão do assalariamento na profissão, e menos informações ainda sobre o processo de trabalho. Sua hipótese é de que à época do estudo originalmente uma tese de mestrado apresentada em 1972 - a proporção de arquitetos autônomos na cidade de São Paulo não ultrapassava os 10\% numa população estimada em dois mil profissionais. Mas como observava prudentemente o autor, "a hipótese exige comprovação empírica quantitativa" (Durand, s.d., p. 103). Quanto ao que Durand chama de "processo objetivo de proletarização" - conteúdo do trabalho, status, remuneração e/ou posição hierárquica cada vez mais próximos daqueles dos trabalhadores manuais -, ele lembra o caráter introdutório do estudo para justificar a "impossibilidade de um juízo categórico sobre a tendência à proletarização, em todos os seus aspectos, do arquiteto, pela precariedade dos dados disponíveis" (Durand, s.d., p. 105). As estimativas do autor sobre assalariamento dos arquitetos são, provavelmente, exageradas; de qualquer forma, no Censo de 1981 do Conselho Federal de Engenharia e Arquitetura, aproximadamente 74\% dos 5.512 arquitetos que responderam ao questionário (numa população estimada de 23.379 profissionais) declarou pertencer à categoria "dos autônomos, sócios, proprietários ou diretores"19.

A pesquisa de Luz sobre os contadores (assalariados em empresas, e autônomos em escritórios de contabilidade em Belo Horizonte) é uma das raras que se endereçam ao tema da degradação do trabalho profissional pela introdução de nova tecnologia (computadores). Optando por uma abordagem longitudinal, a autora comparou o trabalho de contadores e de técnicos em contabilidade antes e depois da introdução do computador; e com o auxílio de 
DINIZ, Marli. Repensando a teoria da proletarização dos profissionais. Tempo Social; Rev. Sociol. USP, S. Paulo, 10(1): 165-184, maio de 1998.

uma detalhada lista de atividades executadas pelos 77 entrevistados ela separou-as segundo a predominância de elementos técnicos, susceptíveis de fácil padronização e codificação, ou de elementos de indeterminação, menos susceptíveis de transferência para o computador. A conclusão do estudo é que, isoladamente, "a variável tecnológica parece não ter influência sobre a autonomia, a qualificação e a variabilidade do trabalho (aspectos centrais da tarefa)" (Luz, 1989, p. 15). Os seus efeitos surgem de sua combinação com outras variáveis como, por exemplo, a da hierarquia na organização: a desqualificação de tarefas (perda ou transferência de parte da tarefa para o computador) ocorre basicamente no nível operacional, onde predomina o componente técnico, e a qualificação (criação ou acréscimo de atividade não rotineira ou complexa, sem qualquer transferência para o computador), nos níveis de supervisão, chefia intermediária e direção, onde predomina o componente de indeterminação. Ou seja: o computador elimina, absorvendo-as, as tarefas mais rotineiras, mas sua introdução na área contábil resulta também na criação de outras tarefas mais complexas. Outra conclusão da pesquisa é que a automação não provocou desemprego entre os contadores e, em alguns casos, está criando novos empregos.

Mencione-se, finalmente, a pesquisa de Simões (1989) com uma amostra de engenheiros no Rio de Janeiro. Trata-se de um estudo sobre a posição de classe dos engenheiros, no qual a questão da proletarização é fundamental. A tese da autora é de que os engenheiros assalariados estariam perdendo o controle sobre o processo do seu trabalho, experimentando portanto a alienação técnica que é, em última instância, o critério crucial para a perda da autonomia e para a degradação do trabalho profissional. Para firmar seu argumento Simões utiliza as categorias de alienação econômica, organizacional e técnica formuladas por Larson.

Como foi visto anteriormente, para Larson os profissionais experimentam a alienação econômica e organizacional, mas não a alienação técnica, pois para controlar o processo de trabalho a gerência teria de obter o domínio da mesma expertise, o que normalmente não ocorre. Quando se observa risco de rotinização de trabalho especializado de alto nível, ele ocorre mais como resultado da divisão do trabalho entre profissionais: por exemplo, entre o trabalho de pesquisa e o de aplicação prática ${ }^{20}$. O que Larson quer enfatizar é que, a despeito desta diferenciação interna que gera hierarquias de habilidades, "os germes da alienação técnica são rapidamente dissolvidos em efeitos de uma divisão do trabalho que aparentemente tende a continuar expropriando altos níveis de competência e concentrando-os em relativamente poucas mãos ou mentes" (Larson, 1980, p. 169). Com isso, o conhecimento técnico permanece sob o controle da profissão e dos profissionais. Simões, entretanto, dissolve a distinção entre a alienação técnica e a organizacional: "embora haja sérias limitações à racionalização do trabalho profissional, gerentes com conhecimento técnico teriam certamente condições para redefinir tarefas, impor ritmos e materiais de trabalho que poderiam afetar o conteúdo técnico do
${ }^{20}$ Os exemplos de Larson: "a necessidade de coletar evidência estatística a respeito de terapias ainda incertas requer, no caso da leucemia, a padronização de tratamentos. Após feito o diagnóstico, ao clínico que aceita o protocolo da pesquisa resta apenas a escolha mecânica entre terapias padronizadas, cujos resultados ele apenas registra. A análise é deixada aos planejadores da pesquisa. Uma tendência semelhante ocorre também com a engenharia estrutural: casos excepcionais e processos de investigação que são difíceis de serem analisados são transferidos para técnicos de nível mais alto, hierarquicamente superiores em termos sociais e ideológicos, restando ao engenheiro comum a aplicação de soluções padronizadas" (Larson, 1980, p. 169). 
${ }^{21}$ A questão 29f (Simões, 1989, p. 491) tem a seguinte redação: "Quem decide quanto trabalho você tem que executar, ou o ritmo do seu trabalho durante o dia?" com as seguintes alternativas: a) você; b) outro engenheiro; c) outra engenheira; d) pessoa de outra ocupação (especifique) [grifo nosso]. processo de trabalho" (Simões, 1989, p. 168). Em suma, sua tese, ao contrário da de Larson, é a de que "uma forma de tornar viável a alienação técnica do trabalho profissional é exatamente mantendo o conhecimento dentro dos grupos ocupacionais através das divisões de classe e de hierarquia dentro da categoria" (Simões, 1989, p. 176). Isto posto, restaria a Simões exibir as evidências de que decisões administrativas (redefinir tarefas, impor ritmos e materiais de trabalho) acarretam de fato alienação técnica, sempre que em sua amostra encontrasse engenheiros supervisionando o trabalho de outros engenheiros. Não é o que ela faz; pelo contrário, com base em tabelas destinadas a mostrar como alguns engenheiros tomam decisões sobre o trabalho de outros engenheiros (ritmo e materiais de trabalho), Simões dá por demonstrado o que permanece ainda suposição: a ocorrência de alienação técnica. Uma leitura atenta da pesquisa de Simões mostra exatamente o oposto do que ela dá por demonstrado. De fato, um dos achados da pesquisa é que "o ritmo de trabalho parece ser uma prerrogativa da grande maioria (89,1\%)" (Simões, 1989, p. 193-4). Na verdade a redação da questão n. 29f do questionário (Simões, 1989, p. 491) indica que também a quantidade de trabalho está sob o controle de $89,1 \%$ dos engenheiros, já que ritmo e quantidade comportam a mesma freqüência de respostas no questionário ${ }^{21}$.

\section{Conclusão}

A tese da proletarização dos profissionais é apenas a versão mais radical de certa linha de análise que descobre sob as transformações por que têm passado as profissões "clássicas" ao longo do século uma persistente erosão da autoridade dos experts. Outros autores também atentos a estas mudanças diagnosticam um acentuado processo de "desprofissionalização", termo pelo qual entendem os efeitos cumulativos de fatores (institucionalização do trabalho profissional, clientela mais informada e mais exigente, introdução de tecnologia sofisticada que reduz o coeficiente de intervenção individual do profissional etc.) que restringem a autonomia e a autoridade socialmente sancionada que, no passado, teriam gozado os profissionais "liberais" para estabelecer as condições de seu trabalho, os procedimentos técnicos do seu mister, o preço dos serviços e o padrão de relacionamento com a clientela.

Ora, os argumentos sobre a erosão da autoridade profissional parecem bem menos convincentes ou fundamentados quando vistos da ótica de um determinado padrão global de autoridade. Não existem evidências de que a autoridade profissional tenha perdido espaço para outros tipos de autoridade, e é em termos desta eficiência social relativa que a tese da "desprofissionalização" deve ser avaliada (Beckman, 1990). Tome-se, para exemplo, duas dimensões desta variável: a) a importância relativa das conseqüências de ações orientadas pela autoridade profissional, em comparação com a de outros tipos de autoridade; b) o valor de troca da autoridade profissional para a aquisição de outros tipos de autoridade. 
Como observa Beckman, se a política econômica de um país é formulada por um pequeno número de economistas profissionais, as conseqüências desta formulação tem uma tal magnitude que só por um equívoco pode-se falar em "desprofissionalização" com base no crescente assalariamento dos médicos. Da mesma forma, se os títulos profissionais são uma "moeda" cada vez mais forte para a aquisição de autoridade burocrática em diferentes tipos de organização, não há como falar em "desprofissionalização" tendo em vista a frequiência com que os profissionais são encontrados em posições burocráticas (cf. Beckman, 1990, p. 135).

Bem observadas as tendências, as profissões continuam a exercer controle sobre esferas fundamentais do saber, e por isso dispõem de um "mandato de conhecimento" que lhes confere autoridade técnica e moral para estabelecer para toda a sociedade definições sobre aspectos ou segmentos particulares da realidade - o que é "saúde" ou "doença" e, de maneira mais geral, o que é ordem ou desordem (Halliday, 1985). Isto posto, é analiticamente mais adequado e empiricamente mais correto detectar nas mudanças por que têm passado as profissões a fase mais avançada do mesmo processo de racionalização formal que nos primórdios do capitalismo competitivo criou as condições de mercado para os primeiros movimentos profissionais. Ritzer e Walczak, com quem abri este artigo, estão corretos na descrição das mudanças; todavia, o diagnóstico da "desprofissionalização" parece estar amplamente equivocado.

Recebido para publicação em setembro/1997

DINIZ, Marli. Rethinking the theory of professionals' proletarianization. Tempo Social; Rev. Sociol. USP, S. Paulo, 10(1): 165-184, may 1998.

ABSTRACT: The author analyzes the theory of the professionals' proletarianization with the objective of verifying to what extent it captures the real processes of change that have been affecting the professions. The central questions that the author addresses are whether professionals employed by public and private bureaucracies preserve their technical qualifications, and whether they preserve control over their highly specialized knowledge and over their work process. Using an extensive bibliography on professional work in several industries (metal, mechanic, electronic), the author concludes that the evidences of growing employment of some of the liberal professions does not constitute support for the thesis of the professionals' proletarianization when this term is appropriately understood. The research has shown that even when the professional employee loses the control over his work conditions, he keeps the control over his own work, that is, he conserves his technical autonomy.

UNITERIMS: professionals, proletarianization, deprofessionalization, technical autonomy. 


\section{REFERÊNCIASBIBLIOGRÁFICAS}

Bell, Daniel. (1977) O Advento da sociedade pós-industrial. São Paulo, Cultrix.

Beckman, Savante. (1990) Professionalization: borderline autority and autonomy in work. In: Burrage, Michael \& Torstendahl, Rolf (eds.). London, Sage Publications.

Braverman, Harry. (1977) Trabalho e capital monopolista - a degradação do trabalho no século XX. Rio de Janeiro, Zahar.

Cavestro, William. (1984) Automatization, organization du travail et qualification dans les PME: le cas des machines-outils à commande numérique. Sociologie du Travail, 4: 434-446.

Dicionário das Profissões. (1981) $3^{\mathrm{a}}$ ed. São Paulo, CIEE (Centro de Integração Empresa Escola).

DENT, Mike. (1993) Professionalism, educated labour and the state: hospital medicine and the new manegerialism. The Sociological Review, 41(2): 244-273, May.

DERBER, Charles. (1983a) Managing professionals: ideological proletarization and post-industrial labour. Theory and Society, 12(3): 309-341.

. (1983b) Sponsorship and the control of physicians. Theory and Society, 12(5): 561-601.

DinIZ, Marli. (1995) Os Donos do saber: profissões e monopólios profissionais. Rio de Janeiro, 286 p. Tese (Doutorado). IUPERJ.

Donnangelo, Maria Cecília F. (1975) Medicina e sociedade: o médico e seu mercado de trabalho. São Paulo, Pioneira.

Durand, José Carlos Garcia. (s.d.) A profissão de arquiteto: estudo sociológico. Rio de Janeiro, CREA.

FALABELla, Gonzalo. (1988) Uma discussão teórico-comparativa: análise de experiências internacionais. In: NADER, Ricardo Toledo et alii. Automação e movimento sindical no Brasil. São Paulo, Hucitec, p. 13-24.

FreIDSON, Eliot. (1970) Profession of medicine: a study of applied knowledge. New York, Dodd, Mead and Co.

. (1986) Professional power: a study of the institutionalization of formal knowledge. Chicago, The University of Chicago Press.

. (1993) Professionalism and the occupational principle. In:

(ed.). The professions and their prospects. London, Sage, 19-38.

FREYSSENET, Michel. (1984) La requalification des operateurs et la forme sociale actuelle d'automatization. Sociologie du Travail, 4: 422-433. 
Gagliani, Giorgio. (1981) How many working classes? American Journal of Sociology, 87(2): 259-285, Sept.

GILL, Colin. (1984) Nouvelle techonologie, déqualification et stratégies de l'entreprise. Le débat en Grande-Bretagne. Sociologie du Travail, 4: $558-563$.

HaLliDAY, Terence C. (1985) Knowlwdge mandates: colletive influence by scientific, normative and syncretic professions. The British Journal of Sociology, 36(3): 421-447, Sept.

JONES, Bryn \& WoOD, Stephen. (1984) Qualifications tacites, division du travail et nouvelles technologies. Sociologie du Travail, 4: 407-421.

Kern, Horst \& Schumann, Michael. (1984) Vers une reprofissionalization du travail industriel. Sociologie du Travail, 4: 389-406.

LARSON, Magali S. (1977) The rise of professionalism: a sociological analysis. Berkeley, University of California Press.

(1980) Professionalization and educated labour. Theory and Society, 9(1): 131-175, Jan.

LEE, D. J. (1981) Skill, craft and class: a theoretical critique and a critical case. Sociology, 15(1): 56-78, Feb.

Luz, Talita Ribeiro da. (1989) Microeletrônica e ocupação: o impacto na profissão de contador. Revista de Administração de Empresas, 29(2): 5-18, abril-junho.

Estoques de Profissionais do Nível Superior. (s.d.) Estudos Estatísticos (edição preliminar). Brasília, MEC - Ministério da Educação e Cultura.

PRANDI, Reginaldo. (1982) Os favoritos degradados: ensino superior e profissões de nível universitário no Brasil hoje. São Paulo, Loyola.

Ritzer, George \& Walczak, David. (1988) Rationalization and the desprofessionalization of physicians. Social Forces, 67(1): 1-22, Sept.

Schmitz, Hubert. (1985) A microeletrônica: suas implicações sobre o emprego e o salário. Pesquisa e Planejamento Econômico, 15(3): 639680, dez.

SimõEs, Solange de Deus. (1989) The position of engineers in the brasilian class structure and their industrial and political orientation. $\mathrm{Ph} . \mathrm{D}$. dissertation. London School of Economics and Political Science.

SouzA, Nair Heloisa Bicalho de. (1988) Os efeitos da nova tecnologia nas fábricas. In: NADER, Ricardo Toledo et alii. Automação e Movimento Sindical no Brasil. São Paulo, Hucitec, 87-131.

STARK, David. (1980) Class struggle and the transformation of the labour process. Theory and Society, 9(1): 89-130, Jan. 
Whalley, Peter. (1984) Deskilling engineers? the labour process, labour markets and labour segmentation. Social Problems, 32(2): 117-132, Dec.

(1986) Markets, managers, and technical autonomy. Theory and Society, 15(1-2): 233-347.

\& CRAWFORD, Stephen. (1984) Locating technical workers in the class structure. Politics and Society, 13: 239-252.

WiLKInson, Barry. (1984) Technologie, qualifications et formation: une étude de cas sur les machines à commande numérique. Sociologie $d u$ Travail, 4: 447-456.

Zussman, Robert. (1984) The middle-levels: engineers and the working middle class. Politics and Society, 13(3): 217-237. 